\title{
On the Growing Opportunity to Use Sentiment Analysis to Support Artificial Intelligence Applications in Healthcare
}

\author{
David B Fogel* \\ Chief Scientist, Trials.ai, San Diego, United States
}

Submission: February 22, 2019; Published: February 28, 2019

*Corresponding author: David B Fogel, Chief Scientist, Trials.ai, 1510 Front St., Suite 400, San Diego, CA 92101, United States, Email: david@trials.ai

Abstract

Sentiment analysis involves the automatic assessment of emotional content in communications. Primary analysis has focused on identifying positive, negative, or neutral emotional states. More sophisticated analyses identify states associated with specific human emotions, such as anxiety, hostility, or confidence. There are at least two clear opportunities to employ sentiment analysis in healthcare applications: (a) preparing documents for participants in clinical trials, and (b) patient monitoring. Successful applications of sentiment analysis may increase clinical trial retention and help identify those patients who would benefit from intervention.

\section{Introduction}

There has been a long-standing interest in assessing emotional states in communication [1,2]. Early applications, from the 1960s, were quite limited at least in part because of the expense and relatively slow processing power of existing computers. Now, five decades since Gottschalk \& Gleser [2] introduced, in 1969, the concept of assessing a person's psychological states based on the words and phrases that he or she used, the tools for analyzing sentiment have advanced to a more practical and general utility across the field of healthcare.

Modern sentiment analysis programs use natural language processing and other artificial intelligence (AI) tools to automatically process text-based communications [3]. The analysis is conducted generally by looking for words and phrases that are associated with specific identified sentiments, and possibly with the results of natural language understanding algorithms that seek to put the words and phrases in context. These approaches are described generally by the terms lexical and contextual, where the former is at the level of words and phrases outside of the context of the communication. One example to illustrate the difference between lexical and contextual interpretation comes when comparing the sentences "I'm anxious to meet you" to "I'm eager to meet you." In context, each is normally viewed as meaning the same thing, but lexically the former evokes anxiety while the later evokes confidence. Both lexical and contextual processing has been shown to be impactful on human behavior and opinion (e.g.,
[4-7] and many others) and thus both lexical and contextual approaches to sentiment analysis are presumed valuable.

\section{Opportunities in Healthcare}

From my own experience over 20 years with sentiment analysis [8] and also AI applications in medicine and healthcare (e.g., [912]), I believe there are at least two immediate opportunities to apply sentiment analysis in health care for the benefit of patients and healthcare providers, as well as pharmaceutical and medical device companies: (a) Preparing documents for participants in clinical trials, and (b) Patient monitoring.

Clinical trials are often costly and time consuming [13]: costs often exceed $\$ 2.5$ billion and require more than a decade from first clinical trials to an FDA approval. One of the many reasons that clinical trials face such hurdles is patient/subject retention. The average dropout rate in clinical trials is approximately $30 \%$ [14] and many trials fail to meet enrollment goals [15]. Patients feeling respected is known to be associated with greater retention [12]. In part, patients report greater satisfaction when receiving understandable documents [16], with information regarding the clinical trial they are considering [17], along with information about the principal investigator [18]. I believe these observations lay the foundation for a broader approach to ensuring that patients feel respected and appreciated, which can come in more carefully choosing the exact language of the documents that are provided. Sentiment analysis tools may be helpful in identifying 
the likely emotional reaction of clinical trial candidates to the materials that the clinical trial is presenting and may be helpful in crafting alternative language that conveys the same information but with increased likelihood of imparting feelings of confidence, compassion, and optimism. This may be particularly appropriate given that most documents provided to potential participants are replete with medical terms that are likely to increase anxiety for those without a familiarity with medical terminology. Affecting retention rates positively by improving patient sentiment may become an important ingredient in reducing the cost and duration of clinical trials.

Separately, there are increasing opportunities to employ outpatient care, reducing the burden on hospitals and other care facilities; however, monitoring patient health, even at a distance, remains crucial. New research is showing that patients, including the elderly, may be willing to relate to avatars or other "virtual agents" [19], which are essentially digital characters. Avatars have been used to help Type II diabetics adhere to medication schedules [20], while Rehm et al. [21] identified opportunities for using avatars in mental health interventions. For this latter application, it is important to identify changes in the subject's emotional state that could reflect changes in mental health. Sentiment analysis tools offer the potential to track interactions with an avatar, entries in an electronic diary, or other communications, to establish baseline variations in evoked emotions. Then, using statistical quality control techniques, changes in those evoked emotions that are suggestive of the need to intervene may be identified. For example, a communication two days post-surgery about a patient's perceived levels of pain might suggest the need for further investigation or treatment if the patient's communication reveals increased level of evoked anxiety or depression, or a trend to higher levels of these expressed emotions. When combined with emotion-recognition based on facial features [22,23], a more accurate representation of the patient's emotional well-being may be constructed.

\section{Conclusion}

The opportunities to employ artificial intelligence to support more effective health care will assuredly grow in coming years. Many of the existing opportunities focus on diagnostics, genetic analysis, or other important aspects of providing quality care. But these are purely clinical rather than emotional in character. Yet, a patient's emotional state may be associated strongly with a willingness to participate in research and his or her wellbeing during care. Sentiment analysis has not received as much attention as other AI concepts in the context of providing superior healthcare. My hope is that it receives greater attention in the future.

\section{Acknowledgement}

Thanks to Tom Walpole for his helpful comments on this article.

\section{Conflict of Interest}

David Fogel serves as chief scientist of Trials.ai, a technology company that employs artificial intelligence methods to improve the design and execution of clinical trials. He also serves as a director and co-founder of Effect Technologies, Inc., which offers sentiment analysis tools for a wide variety of applications, including those in healthcare.

\section{References}

1. Stone PJ, Dunphy DC, Smith MS (1996) The general inquirer: a computer approach to content analysis. MIT Press, Cambridge, United Kingdom.

2. Gottschalk LA, Gleser GC (1969) The measurement of psychological states through the content analysis of verbal behavior. Univ California Press, Los Angeles, California, United States.

3. Cambria E (2016) Affective computing and sentiment analysis. IEEE Intelligent Systems 31(2): 102-107.

4. Gui B, Park J, Konana P (2012) Research note - the impact of external word-of-mouth sources on retailer sales. Inform Syst Res 23(1).

5. Bollen J, Mao H, Zeng XJ (2010) Twitter mood predicts the stock market. J Computational Science 2: 1-8.

6. Gunter B, Kteyo N, Atansova D (2014) Sentiment analysis: a marketrelevant and reliable measure of public feeling? Int J Market Res 56(2): 231-247.

7. Salehan M, Kim DJ (2016) Predicting the performance of online consumer reviews: a sentiment mining approach to big data analytics. Decision Support Syst 81: 30-40.

8. Volcani Y, Fogel DB (2001) System and method for determining and controlling the impact of text. USPTO \#7,136,877.

9. Gehlhaar DK, Verkhivker GM, Rejto PA, Sherman CJ, Fogel DB, et al. (1996) Molecular recognition of the inhibitor AG-1343 by HIV1 protease: conformationally flexible docking by evolutionary programming. Chem Biol 2: 317-324.

10. Fogel DB, Wasson EC, Boughton EM, Porto VW (1998) Evolving artificial neural networks for screening features from mammograms. Artif Intell Med 14: 317-326.

11. Fogel DB, Fogel GB (2012) Method and device for tinnitus masking. USPTO \#8273034.

12. Fogel DB (2018) Factors associated with clinical trials that fail and opportunities for improving the likelihood of success: a review. Contemp Clin Trials Commun 11: 156-164.

13. DiMasi JA, Grabowski HG, Hansen RW (2015) The cost of drug development. N Engl J Med 372(20): 1972.

14. Tointon A (2016) The issue of patient retention. CenterWatch Online.

15. Campbell MK, Snowdon C, Francis D, Elbourne D, McDonald AM, et al. (2007) Recruitment to randomised trials: strategies for trial enrollment and participation study: the STEPS study. Health Technol Assess 11(48): iii, ix-105.

16. Davis TC, Holcombe RF, Berkel HJ, Pramanik S, Divers SG (1998) Informed consent for clinical trials: a comparative study of standard versus simplified forms. J Natl Cancer Inst 90: 668-674.

17. Sood A, Prasad K, Chhatwani L, Shinozaki E, Cha SS, et al. (2009) Patients' attitudes and preferences about participation and recruitment strategies in clinical trials. Mayo Clin Proc 84: 243-247. 
18. Morris BJ, Richards JE, Archer KR, Lasater M, Rabalais D, et al. (2014) Improving patient satisfaction in the orthopaedic trauma population. J Orthop Trauma 28: e80-84

19. Shaked NA (2017) Avatars and virtual agents - relationship interfaces for the elderly. Healthcare Technol Lett 4(3): 83-87.

20. Lesin S (2016) 'Frederick' medical virtual assistant'. Final project, Software Engineering Department, Afeka College for Engineering, Israel.

21. Rehm IC, Foenander E, Wallace K, Abbott JM, Kyrios M, et al. (2016) What role can avatars play in e-mental health interventions? Exploring new models of client-therapist interaction. Front Psychiatry 7: 186.
22. Wegrzyn M, Vogt M, Kireclioglu B, Schneider J, Kissler J (2017) Mapping the emotional face. How individual face parts contribute to successful emotion recognition. PLOS One 12(5): e0177239.

23. Rao SJ, Wang Y, Cottrell GW (2016) A deep Siamese neural network learns the human-perceived similarity structure of facial expressions without explicit categories. In: Proceedings of the $38^{\text {th }}$ Annual Conference of the Cognitive Science Society. Cognitive Science Society: TX, Austin, Australia pp. 217-222.

\section{Your next submission with Juniper Publishers will reach you the below assets}

- Quality Editorial service

- Swift Peer Review

- Reprints availability

- E-prints Service

- Manuscript Podcast for convenient understanding

- Global attainment for your research

- Manuscript accessibility in different formats

( Pdf, E-pub, Full Text, Audio)

- Unceasing customer service

Track the below URL for one-step submission https://juniperpublishers.com/online-submission.php 